Research Paper:

\title{
The Effect of Aromatherapy and the Benson Relaxation Technique on the Anxiety of Patients With Acute Coro- nary Syndrome: Randomized Controlled Trial
}

\author{
Samaneh Sahrayi Zarghi ${ }^{1,2}$ (D), Tahereh Najafi Ghezeljeh ${ }^{1,2^{*}}$ (i), Mahboubeh Rasouli ${ }^{3}$ (iD)
}

1. Nursing Care Research Center, Iran University of Medical Sciences, Tehran, Iran.

2. School of Nursing and Midwifery, Iran University of Medical Sciences, Tehran, Iran.

3. Department of Biostatistics, School of Public Health, Iran University of Medical Sciences, Tehran, Iran.

\begin{tabular}{|c|c|}
\hline $\begin{array}{l}\text { Use your device to scan } \\
\text { and read the article online }\end{array}$ & Cottent Sahrayi Zarghi, S., Najafi Ghezeljeh, T., Rasouli, M., 2020. The Effect of Aromatherapy and the Benson Relax- \\
\hline 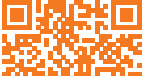 & $\begin{array}{l}\text { ation Technique on the Anxiety of Patients With Acute Coronary Syndrome: Randomized Controlled Trial. Journal of Client- } \\
\text { Centered Nursing Care, 6(2), pp. 109-116. https://doi.org/10.32598/JCCNC.6.2.34.2 }\end{array}$ \\
\hline astang & doijhttps://doi.org/10.32598/JCCNC.6.2.34.2 \\
\hline
\end{tabular}

\section{(c) (1) (3)}

Article info:

Received: 15 Feb 2020

Accepted: 02 Apr 2020

Published: 01 May 2020

Keywords:

Acute coronary syndrome, Anxiety, Aroma, Lavender, Muscle relaxation, Randomized controlled trial

\begin{abstract}
A B S T R A C T
Background: Anxiety is a common symptom in patients with the Acute Coronary Syndrome (ACS), which can threaten their quality of life. This study was done to compare the effects of aromatherapy using lavender and Benson's relaxation technique on the anxiety of patients with ACS

Methods: In this randomized clinical trial, 96 patients with ACS were selected using consecutive sampling method from two hospitals in an urban area of Iran. The patients were randomly assigned to three groups of aromatherapy $(n=32)$, Benson's relaxation $(n=32)$, and control $(n=32)$ using the block size of six. The interventions were performed on two consecutive days, once a day for 20 min. Anxiety was measured before and immediately after the intervention using the Spielberger's Anxiety Inventory. Data were analyzed using the Chi-square test, Fisher's exact test, one-way Analysis Of Variance (ANOVA), Bonferroni post hoc test, and mixed-model repeated-measures ANOVA with a $3 * 2 * 2$ design by the SPSS V. 16 .

Results: There was no statistically significant difference in state and trait anxiety scores between the groups after the intervention on different time points $(\mathrm{P}>0.05)$. The time $(\mathrm{P}=0.001)$, group-day interaction $(\mathrm{P}=0.005)$, and time (pretest and posttest) and day $(\mathrm{P}=0.029)$ effect on state anxiety was statistically significant. The time $(\mathrm{P}<0.001)$ and the group-day interaction $(\mathrm{P}<0.001)$ effect on trait anxiety was statistically significant.

Conclusion: Benson's relaxation method and lavender aromatherapy did not significantly reduce anxiety in patients with ACS. Considering the anxiety and its complications in patients with ACS and the importance of its management, further studies are needed to determine appropriate care and treatment for these patients and reduce their anxiety.
\end{abstract}

* Corresponding Author:

Tahereh Najafi Ghezeljeh, PhD.

Address: School of Nursing and Midwifery, Iran University of Medical Sciences, Tehran, Iran.

Tel: +98 (21) 88882886

E-mail:najafi.t@iums.ac.ir 


\section{Highlights}

- Acute Coronary Syndrome (ACS) is the most serious form of coronary artery disease.

- Anxiety is one of the most frequently observed problems in patients with ACS.

- Relaxation as an affordable method can increase the sense of wellbeing and reduce hospital stay and mortality.

- The effects of lavender on anxiety have been reported in previous studies.

- Despite the presence of changes in the anxiety after the interventions, the Benson relaxation technique and lavender aromatherapy were not effective on state and trait anxiety compared with the control group.

- The improvement in anxiety was greater on the second day compared with the first day and it was not dependent on the group.

\section{Plain Language Summary}

Benson relaxation and aromatherapy are non-invasive and non-prescriptive therapeutic methods for reducing anxiety levels. However, in this study, both interventions were not effective, which can be related to the patients' condition who experienced the acute phase of coronary heart disease. Further studies are needed to determine appropriate care and treatment for these patients to reduce their anxiety.

\section{Introduction}

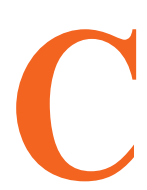

ardiovascular diseases are the main cause of death globally and are a major health threat worldwide (Virani et al. 2020). Acute Coronary Syndrome (ACS) is the most serious form of coronary artery disease (Hinkle \& Cheever 2018). It is estimated that the annual incidence of ACS is 1 in 80 or 1 in 170 in the European general population (Henderson 2014).

Anxiety is one of the most frequently observed problems in patients with ACS, which occurs in approximately $20 \%-50 \%$ of patients (Celano et al. 2016). Complex care and advanced equipment, threatening disorder, presence of unfamiliar people and devices, lack of space and time perception, permanent monitoring of vital signs and cardiac activity, and unknown odors are among the stressors in the Cardiac Care Unit (CCU) (Heidemann et al. 2011). Post-ACS anxiety has various consequences and is related to the high probability of cardiovascular and non-cardiovascular mortality and can affect the recovery process after ACS, hospital stay duration, and complications (Lissåker et al. 2019; Li et al. 2019). Anxiety can be relieved using antidepressants, benzodiazepines, psychotherapy (Celano et al. 2016), non-pharmacological measures, and complementary medicine (Ravindran \& da Silva 2013).

Relaxation as an affordable method can increase the sense of wellbeing and reduce hospital stay and death rate (Pagnini et al. 2013; Najafi Ghezeljeh 2016). In Benson's muscle relaxation technique, unlike other relaxation methods, muscle contraction is not used. This is important in patients with heart diseases because muscle contraction increases heart rate, blood pressure and respiratory rate, and consequently the heart workload. This technique should be done in a relaxed, comfortable environment with mental focus and a positive attitude to obtain the appropriate effect (Payne \& Donaghy 2010). The effect of Benson's muscle relaxation technique has been reported (Tahmasebi et al. 2015).

Aromatherapy refers to the use of oil or perfume extracted from aromatic plants for therapeutic purposes, which can stimulate the olfactory system and reduce anxiety symptoms (Ali et al. 2015). Lavender is one of the most widely used plants because of its sedative, antidepressant, antispasmodic, antibacterial, and local anesthetic effects (Erland \& Mahmoud 2016). The effects of lavender on anxiety have been reported in previous studies (Hosseini et al. 2016; Seifi et al. 2014). 
There is a need to study different methods for patient care and choose the most effective one to manage symptoms and provide evidence-based care. This study was done to compare the effects of lavender and Benson's muscle relaxation technique in patients with ACS.

\section{Materials and Methods}

\section{Design}

This parallel randomized clinical trial was performed in three groups in patients with the primary diagnosis of ACS admitted to two CCUs in an urban area of Iran from April to September 2018.

\section{Sampling and patient recruitment}

Patients were recruited using a consecutive sampling method and the subjects meeting the inclusion criteria were selected until the required sample size was achieved. Inclusion criteria were passing $24 \mathrm{~h}$ after the admission, ability to speak in Persian, the age of 18 years and over, no history of allergies, mental disorders, and sensitivity to essential oils, the absence of deficiencies in olfactory and respiratory systems, no presence of psychiatric or anxiety disorders according to the self-report and medical record, no surgical or therapeutic interventions, such as angiography on the day of the intervention, no muscle paralysis, no addiction to alcohol and drug abuse, and anxiety reported by the patient.
To calculate the sample size using a repeated-measures analysis of variance (ANOVA) with a $3 * 2 * 2$ design, the parameters were specified as a general guideline considering the power of 0.80 , alpha of 0.05 , and the effect size of 0.25 . The sample size was estimated to be 27 patients per group. Considering the probability of sample attrition of $20 \%$, the sample size was considered 32 cases in each group. One hundred eighty-five patients with ACS meeting the diagnostic criteria entered the assessing process for eligibility criteria, and after the exclusion, a total of 96 patients participated in the study. There was not any attrition (Figure 1).

\section{Random allocation}

The randomized block method with a block size of six and the 1:1 ratio was used. In this method, the different forms of the three groups were written on cards, and each was placed inside a sealed opaque envelope. The sequence of groups in each block was determined by a statistician using the table of random numbers. A nurse who was unaware of the study process selected an envelope. This was continued until the desirable number of the samples was chosen.

\section{Intervention protocol}

The patients in the control group received routine care. They were asked to stay in bed for $20 \mathrm{~min}$. In addition to routine care, the patients in the lavender aromatherapy

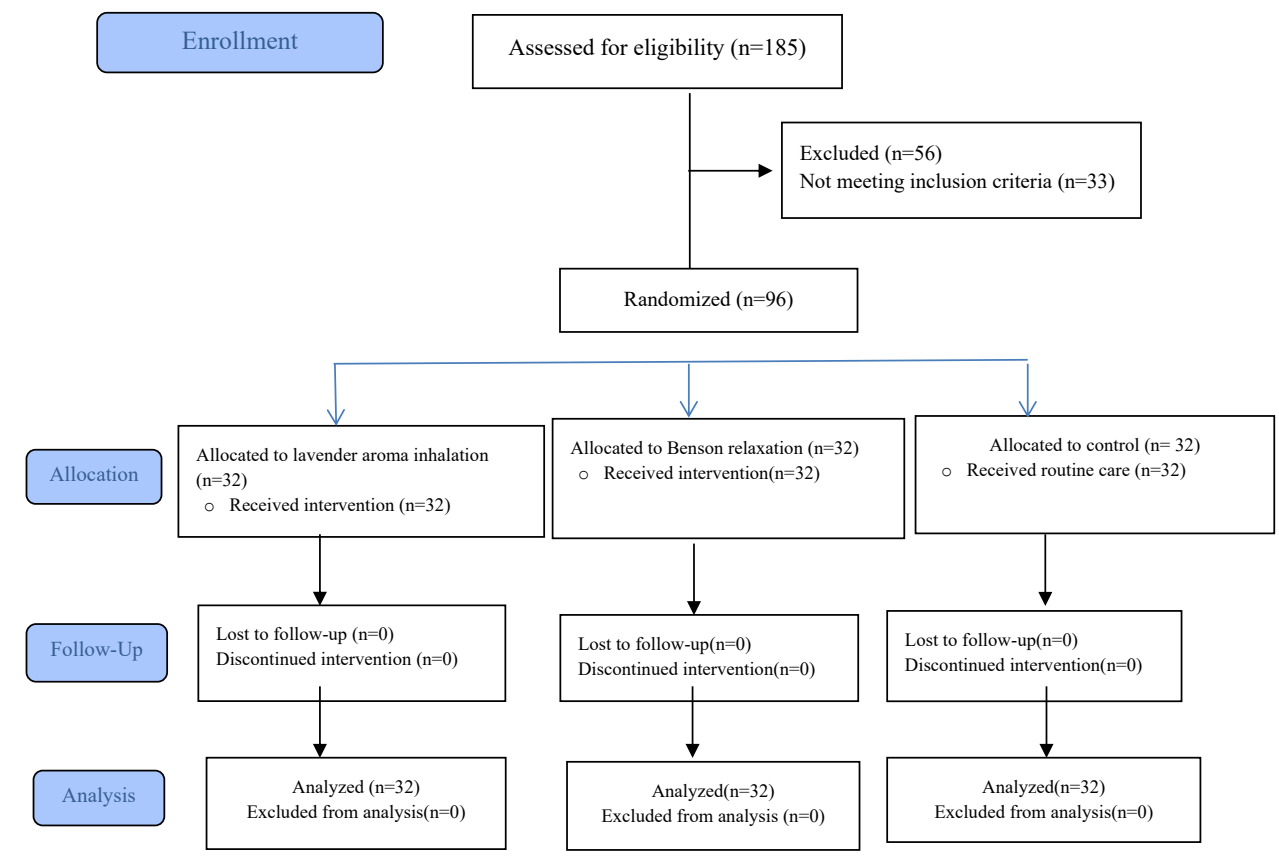

Figure 1. The study process 
group were asked to inhale and smell a 10-in-10 gauze containing two drops of lavender extract $(2 \%)$ produced by the Barij Essence Pharmaceutical Co ${ }^{\circledR}$ for $20 \mathrm{~min}$. The gauze was placed at a distance of $5 \mathrm{~cm}$ from the patients' nose and attached to their clothing. This procedure was performed once a week between 18:00 and 20:00 for 2 consecutive days and the researcher monitored its implementation. Since there was a possibility of contaminating the patients of the control and Benson relaxation groups with the lavender aroma, no patient was recruited for the other groups from the unit, in which the patients undergoing lavender aromatherapy were hospitalized.

In the Benson relaxation group, the technique was fully taught to the patients through lecture and demonstration by the qualified researcher, and ambiguities were resolved. The technique was performed as follows: the patients laid down in a comfortable position in a quiet environment, they closed their eyes and slowly relaxed their muscles from head to toe, removed distracting thoughts from their minds as much as possible, and repeated a word that always reminded them of calm, such as God, love, and sea. Then, they performed the inspiration through the nose and exhaled through the mouth, and whispered the word at the time of exhalation. They performed the technique for $20 \mathrm{~min}$, and slowly opened their eyes, but did not move for a few minutes. The patient could stop the procedure at any time in case of feeling discomfort. The audio file containing instructions for relaxation exercises was provided through the MP3 player and headphones. In addition to routine care, the Benson relaxation procedure was performed once a day between 18:00 and 20:00 for two consecutive days by the patients and under the supervision of the researcher.

\section{Data collection}

Data were collected using the demographic and disease form, the Spielberger Anxiety Inventory (SAI), and the State-Trait Anxiety Inventory (STAI). STAI includes two distinct parts of state and trait anxiety and contains 20 questions for each part. Each question is scored based on a Likert type scale from 1 to 4 . The presence of anxiety is scored by $4,3,2,1$, and the absence of anxiety is scored in reverse order. The minimum score is zero and the maximum score is 80 and higher values indicate more anxiety (Julian 2011). The validity and reliability of the STAI in Iran have been confirmed and the Cronbach's alpha coefficient for the state and trait parts are reported as 0.91 and 0.90, respectively (Mahram 1993). In the current study, the Cronbach's alpha coefficient to determine the internal consistency of the tool was calculated 0.732 and 0.736 for the state and trait sections, respectively. The STAI was collected before and after the intervention. The responsible researcher for data collection was blind to the type of intervention.

\section{Data Analysis}

To examine the normal distribution of data, the Kolmogorov-Smirnov test was used. The Chi-square test, Fisher's exact test, one-way ANOVA, and paired t-test were used to compare variables. The effects were estimated using a mixed model and repeated measures ANOVA with a $3 * 2 * 2$ design with the group as a between factor (lavender vs. Benson vs. control) and time (both two days and pre- and post-measurements) as a within factor. The significance level was set at $\mathrm{P}<0.05$. Data analysis was carried out via the SPSS V. 13.

\section{Results}

According to Table 1, no statistically significant differences were found between the three groups in terms of demographic and disease characteristics and the groups were homogeneous.

The results of one-way ANOVA showed no statistically significant differences between the groups in terms of changes in state and trait anxiety scores on the first and second days. Also, in the Benson relaxation group, statistically significant differences were found between the mean scores of state and trait anxiety before and after the intervention on the first $(\mathrm{P}=0.005)$ and second $(\mathrm{P}=0.001)$ days (Table 2).

According to Table 3, time effect $(\mathrm{P}=0.001)$, groupday interaction effect $(\mathrm{P}=0.005)$ and time (pretest and posttest)-day interaction effect $(\mathrm{P}=0.029)$ on state anxiety were statistically significant. The Bonferroni post hoc test indicated statistically significant differences between the mean scores of state anxiety in pre- and post-test on the first day in the Benson group $(\mathrm{P}=0.017)$, pre- and post-test on the first day in the aromatherapy group ( $\mathrm{P}=0.04)$, pre- and post-test on the second day in the Benson group $(\mathrm{P}=0.003)$, and pre- and post-test on the second day in the aromatherapy group $(\mathrm{P}=0.035)$.

According to Table 3, the time effect $(\mathrm{P}<0.001)$ and group-day interaction effect $(\mathrm{P}<0.001)$ on trait anxiety was statistically significant. Bonferroni post hoc test indicated that there were significant differences between the mean scores of trait anxiety in pre- and post-test on the first day in the aromatherapy group $(\mathrm{P}=0.003)$, preand post-test on the second day in the Benson group 
Table 1. Demographic characteristics of the patients with acute coronary syndrome

\begin{tabular}{|c|c|c|c|c|c|}
\hline \multirow{2}{*}{\multicolumn{2}{|c|}{ Variables }} & \multicolumn{3}{|c|}{ Mean \pm SD / No. (\%) } & \multirow{2}{*}{$\mathbf{P}$} \\
\hline & & Benson Muscle Relaxation & Aromatherapy & Control & \\
\hline \multicolumn{2}{|c|}{ Age (y) } & $60.06 \pm 11.87$ & $60.90 \pm 13.59$ & $55.71 \pm 20.12$ & $0.20 *$ \\
\hline \multicolumn{2}{|c|}{ Disease duration, month } & $24.36 \pm 46.78$ & $41.89 \pm 82.43$ & $21.21 \pm 81.56$ & $0.32^{*}$ \\
\hline \multicolumn{2}{|c|}{ Weight } & $74.25 \pm 14.77$ & $72.12 \pm 11.41$ & $76.87 \pm 12.24$ & $0.46^{*}$ \\
\hline \multirow{2}{*}{ Gender } & Male & $18(56.3)$ & $21(65.6)$ & $25(78.1)$ & \multirow{2}{*}{$0.20 * *$} \\
\hline & Female & $14(47.3)$ & $11(34.4)$ & $7(21.9)$ & \\
\hline \multirow{3}{*}{ Marital status } & Single & $5(15.6)$ & $3(9,4)$ & $2(6,3)$ & \multirow{3}{*}{$0.40^{* * *}$} \\
\hline & Married & $19(59.4)$ & $21(56,6)$ & $26(81.3)$ & \\
\hline & Widow-divorced & $8(25)$ & $8(25.1)$ & $4(12.6)$ & \\
\hline \multirow{3}{*}{ Education level } & Illiterate & $11(36.7)$ & $16(50.0)$ & $9(28.1)$ & \multirow{3}{*}{$0.38^{* *}$} \\
\hline & Under diploma & $9(30)$ & $5(15.6)$ & $10(31.3)$ & \\
\hline & Diploma and higher & $10(33.3)$ & $11(34.4)$ & $13(40.6)$ & \\
\hline \multirow{4}{*}{ Occupational status } & Unemployed & $2(6.5)$ & $4(12.5)$ & $4(12.5)$ & \multirow{4}{*}{$0.48^{* * *}$} \\
\hline & Employed & $14(45.2)$ & $13(40,6)$ & $19(59.4)$ & \\
\hline & Housewife & $8(25.8)$ & $11(34.4)$ & $6(18.7)$ & \\
\hline & Retired & $7(22.5)$ & $4(12.5)$ & $3(9.4)$ & \\
\hline \multirow{3}{*}{ Income adequacy } & Sufficient & $4(12.5)$ & $13(41.9)$ & $10(31.3)$ & \multirow{3}{*}{$0.07^{* *}$} \\
\hline & Somewhat & $13(40.6)$ & $6(19.4)$ & $12(37.5)$ & \\
\hline & Inadequate & $15(46.9)$ & $12(38.7)$ & $10(31.3)$ & \\
\hline \multirow{2}{*}{ Family history } & Yes & $20(62.5)$ & $22(68.8)$ & $17(53.1)$ & \multirow{2}{*}{$0.47^{* *}$} \\
\hline & No & $12(37.5)$ & $10(31.2)$ & 15 (46.9) & \\
\hline \multirow{2}{*}{ CCU hospitalization history } & Yes & $12(37.5)$ & $16(50.0)$ & $16(50.0)$ & \multirow{2}{*}{$0.51^{* *}$} \\
\hline & No & $20(62.5)$ & $16(50.0)$ & $16(50.0)$ & \\
\hline \multirow{2}{*}{ Smoking } & Yes & $6(18.8)$ & $6(18.8)$ & $5(15.6)$ & \multirow{2}{*}{$0.93^{* *}$} \\
\hline & No & $26(81.3)$ & $26(81.3)$ & $27(84.4)$ & \\
\hline
\end{tabular}

$(\mathrm{P}=0.001)$, and pre- and post-test on the second day in the aromatherapy group $(\mathrm{P}=0.027)$.

\section{Discussion}

In this study, despite the presence of changes in the anxiety after the interventions, Benson relaxation and lavender aromatherapy were not effective on state and trait anxiety compared with the control group. It should be noted that there was a time effect so that the improvement in anxiety was greater on the second day compared with the first day, independently from the group. Benson relaxation and aromatherapy are non-invasive and nonprescriptive therapeutic methods for reducing anxiety levels. However, in this study, both interventions were not effective and it can be related to the patients' condition who experienced the acute phase of coronary heart disease. Patients with ACS have stresses and concerns about both the acute and critical nature of their illness. On the other hand, conditions and environments of the CCU are different from other parts of the hospital or outpatient departments, which can affect patients' focus for relaxation. In line with this study, Elliott (1994) reported that there was no significant difference regarding anxiety and physiological and psychological variables in coronary care patients in the music and muscle relaxation group.

In contrast, Kiani et al. (2017) found that after Benson relaxation, the mean and standard deviation of anxiety scores were statistically different between the two groups and relaxation was effective in reducing anxiety in hemodialysis patients. The differences between the current study and the previous one can be related to the various research population, the nature of anxiety, the acute na- 
Table 2. Comparison of the mean score of state and trait anxiety in the groups before and after the intervention

\begin{tabular}{|c|c|c|c|c|c|c|}
\hline \multirow{2}{*}{ Anxiety } & \multirow{2}{*}{ Days } & \multirow{2}{*}{ Groups } & \multicolumn{3}{|c|}{ Mean \pm SD } & \multirow{2}{*}{$\mathbf{P}$} \\
\hline & & & Benson Muscle Relaxation & Aromatherapy & Control & \\
\hline \multirow{8}{*}{ State } & \multirow{4}{*}{ First } & Before & $56.76 \pm 10.13$ & $52.23 \pm 10.17$ & $50.58 \pm 12.41$ & 0.069 \\
\hline & & After & $47.81 \pm 12.85$ & $47.55 \pm 12.26$ & $48.43 \pm 13.39$ & 0.96 \\
\hline & & $\mathrm{P}$ & 0.005 & 0.11 & 0.50 & \\
\hline & & Changes & $-8.93 \pm 16.38$ & $-5.30 \pm 18.04$ & $-2.50 \pm 20.40$ & 0.39 \\
\hline & \multirow{4}{*}{ Second } & Before & $56.70 \pm 10.89$ & $52.18 \pm 10.24$ & $54.48 \pm 11.47$ & 0.30 \\
\hline & & After & $44.37 \pm 11.05$ & $45.00 \pm 13.50$ & $50.24 \pm 14.10$ & 0.96 \\
\hline & & $\mathrm{P}$ & 0.001 & 0.07 & 0.17 & \\
\hline & & Changes & $-11.55 \pm 16.55$ & $-7.17 \pm 20.01$ & $-4.24 \pm 16.24$ & 0.56 \\
\hline \multirow{8}{*}{ Trait } & \multirow{4}{*}{ First } & Before & $57.12 \pm 9.33$ & $53.66 \pm 9.10$ & $52.99 \pm 11.50$ & 0.21 \\
\hline & & After & $48.42 \pm 11.86$ & $48.03 \pm 11.85$ & $48.93 \pm 13.33$ & 0.18 \\
\hline & & $\mathrm{P}$ & 0.006 & 0.06 & 0.22 & \\
\hline & & Changes & $-9.06 \pm 17.15$ & $-5.80 \pm 17.42$ & $-4.26 \pm 18.66$ & 0.30 \\
\hline & \multirow{4}{*}{ Second } & Before & $56.11 \pm 9.55$ & $52.07 \pm 9.54$ & $55.41 \pm 10.01$ & 0.26 \\
\hline & & After & $44.85 \pm 8.65$ & $45.64 \pm 12.52$ & $50.72 \pm 12.91$ & 0.12 \\
\hline & & $\mathrm{P}$ & 0.001 & 0.07 & 0.11 & \\
\hline & & Changes & $-11.25 \pm 15.47$ & $-6.42 \pm 18.65$ & $-4.68 \pm 15.45$ & 0.31 \\
\hline
\end{tabular}

Table 3. Group, time, and day effects on state and trait anxiety of the patients

\begin{tabular}{cccccccc}
\hline Variables & \multicolumn{3}{c}{ State Anxiety } & \multicolumn{3}{c}{ Trait Anxiety } \\
\cline { 2 - 7 } & $\mathbf{F}$ & $\mathbf{D f}$ & $\mathbf{p}$ & $\mathbf{F}$ & $\mathbf{D f}$ & $\mathbf{p}$ \\
\hline Group & 0.708 & 89.27 & 0.495 & 1.145 & 90.03 & 0.323 \\
\hline Time (pretest-posttest) & 11.910 & 90.76 & 0.001 & 13.592 & 91.33 & $<0.0001$ \\
\hline Days (first and second) & 0.001 & 9.397 & 0.981 & 2.054 & 83.57 & 0.156 \\
\hline Group*time & 1.613 & 90.77 & 0.205 & 0.969 & 91.33 & 0.383 \\
\hline Group*day & 5.715 & 83.97 & 0.005 & 8.487 & 83.56 & 0.000 \\
\hline Day*time & 4.926 & 81.96 & 0.029 & 0.577 & 82.75 & 0.449 \\
\hline Group*time*day & 0.379 & 81.95 & 0.685 & 0.643 & 82.75 & 0.529 \\
\hline
\end{tabular}

ture of ACS in the current study versus chronic condition in hemodialysis patients, and the intervention protocol. Also, in the study of the effect of citrus aroma on the anxiety of ACS patients, Moslemi et al. (2019) showed that the anxiety score of patients decreased significantly. In a study using a combination of lavender, Matricaria recutita, and neroli essential oils for three days in patients with ACS, it was shown that the severity of anxiety decreased following the intervention (Bahrami et al. 2017). The difference between the current research and previous studies could be related to the type of aroma and the intervention protocols. 
In this study, the intervention groups showed no difference regarding anxiety scores after the intervention. In patients with heart failure hospitalized in the CCU, no differences were reported between Benson's relaxation technique and the nature sound (Seifi, Najafi Ghezeljeh \& Haghani 2017). In contrast, in a study, aromatherapy using Lavandula reduced fatigue in patients undergoing hemodialysis more than Benson relaxation technique (Hassanzadeh et al. 2018). Differences in the results of studies can be attributed to differences in the research population and the nature of anxiety.

In this study, subjective variables were measured and further studies by measuring objective indicators are recommended. Also, anxiety was measured twice (before and after the interventions) for two days on hospitalized patients and long-term effects were not investigated. Another limitation of this study was the possibility of the Hawthorne effect.

\section{Conclusion}

Benson's relaxation methods and lavender aromatherapy did not significantly reduce anxiety in patients with ACS. Considering the anxiety and its complications in patients with ACS and the importance of its management, further studies are needed to determine appropriate care and treatment for these patients to reduce their anxiety. It is recommended to conduct more studies with a placebo group, multi pre- and post-intervention measurements over time, measuring objective indicators, and comparing the effect of different kinds of lavender oil.

\section{Ethical Considerations}

\section{Compliance with ethical guidelines}

This study was approved by the Medical Ethics Committee of the Iran University of Medical Sciences, Tehran, Iran (Code: IR.IUMS.REC.1397.009). The patients were informed about the trial before asking for their consent. They signed the written informed consent to participate in this study.

\section{Funding}

The paper was extracted from the MSc. thesis of the first author, Department of critical care nursing, School of Nursing and Midwifery, Iran University of Medical Sciences.

\section{Authors' contributions}

All authors contributed in preparing this article.

\section{Conflict of interest}

The authors declared no conflict of interest.

\section{Acknowledgments}

The authors express their gratitude to the officials and staff of the Cardiology Department of the Rasoul-eAkram hospital and the $15^{\text {th }}$ Khordad Varamin hospital, affiliated to the Social Security Organization, Tehran, Iran.

\section{References}

Ali, B., et al., 2015. Essential oils used in aromatherapy: A systemic review. Asian Pacific Journal of Tropical Biomedicine, 5(8), pp. 601-11. [DOI:10.1016/j.apjtb.2015.05.007]

Bahrami, T., et al., 2017. Effect of aromatherapy massage on anxiety, depression, and physiologic parameters in older patients with the acute coronary syndrome: A randomized clinical trial. International Journal of Nursing Practice, 23(6). [DOI:10.1111/ijn.12601] [PMID]

Celano, C. M., et al., 2016. Anxiety disorders and cardiovascular disease. Current Psychiatry Reports, 18(11), p. 101. [DOI:10.1007/s11920-016-0739-5] [PMID] [PMCID]

Elliott, D., 1994. The effects of music and muscle relaxation on patient anxiety in coronary care unit. Heart \& Lung, 23(1), pp. 27-35. [PMID]

Erland, L. A. E., \& Mahmoud, S. S., 2016. Chapter 57 - Lavender (Lavandula angustifolia) In: V. R. Preedy (ed), Essential Oils in Food Preservation, Flavor and Safety. San Diego Academic Press. [DOI:10.1016/B978-0-12-416641-7.00057-2]

Hassanzadeh, M., et al., 2018. Comparing the effects of relaxation technique and inhalation aromatherapy on fatigue in patients undergoing hemodialysis. Complementary Therapies in Clinical Practice, 31, pp. 210-4. [DOI:10.1016/j. ctcp.2018.02.019] [PMID]

Heidemann, A. M., et al., 2011. The influence of noise levels on the perception of stress in heart disease patients. Revista Brasileira de Terapia Intensiva, 23(1), pp. 62-7. [DOI:10.1590/ S0103-507X2011000100011] [PMID]

Henderson, R. A., 2014. Ischaemic heart disease: Management of non-ST-elevation acute coronary syndrome. Medicine, 42(9), pp. 505-11. [DOI:10.1016/j.mpmed.2014.06.003]

Hinkle, J. L., \& Cheever, K. H., 2018. Brunner \& Suddarth's Textbook of medical-surgical nursing. Philadelphia: Wolters Kluwer. https://books.google.com/books/ about/Brunner_Suddarth_s_Textbook_of_Medical_s. html?id=rbEbkAEACAAJ

Hosseini, S., et al., 2016. Effect of lavender essence inhalation on the level of anxiety and blood cortisol in candidates for open-heart surgery. Iranian Journal of Nursing and Midwifery Research, 21(4), pp. 397-401. [DOI:10.4103/17359066.185582] [PMID] [PMCID] 
Julian, L. J., 2011. Measures of anxiety: State-Trait Anxiety Inventory (STAI), Beck Anxiety Inventory (BAI), and Hospital Anxiety and Depression Scale-Anxiety (HADS-A). Arthritis Care \& Research (Hoboken), 63(Suppl 11), pp. S467-72. [DOI:10.1002/acr.20561] [PMID] [PMCID]

Kiani, F., Hasan Zadeh, M. A., \& Shahrakipour, M., 2017. The effect of Benson's relaxation method on hemodialysis patients' anxiety. Biomedical Research, 28(3), pp. 1075-80. https://bit.ly/3ckEi4p

Li, J., et al., 2020. Anxiety and clinical outcomes of patients with acute coronary syndrome: A meta-analysis. BMJ Open, 10(7), p. e034135. [DOI:10.1136/bmjopen-2019-034135] [PMID] [PMCID]

Lissåker C. T., et al., 2019. Persistent emotional distress after a first-time myocardial infarction and its association to late cardiovascular and non-cardiovascular mortality. European Journal of Preventive Cardiology, 26(14), pp. 1510-8. [DOI:10.1177/2047487319841475] [PMID]

Mahram, B., 1993. [Standardization of Spielberger anxiety test in Mashhad [MSc. thesis] (Persian)]. Tehran: Allameh Tabataba'i University .http://d-lib.atu.ac.ir/site/catalogue/ 64428

Moslemi, F., et al., 2019. Citrus aurantium aroma for anxiety in patients with acute coronary syndrome: A double-blind placebo-controlled trial. The Journal of Alternative and Complementary Medicine, 25(8), pp. 833-9. [DOI:10.1089/ acm.2019.0061] [PMID]

Najafi Ghezeljeh, T., et al., 2015. Effect of benson relaxation on fatigue of nurses working in intensive care units. Journal of Client-Centered Nursing Care, 1(4), pp. 211-7. [DOI:10.15412/J.JCCNC.04010407]

Pagnini, F., et al., 2013. A brief literature review about relaxation therapy and anxiety. Body Movement and Dance in Psychotherapy, 8(2), pp. 71-81. [DOI:10.1080/17432979.2012.750248]

Payne, R. A., \& Donaghy, P. M., 2010. Relaxation techniques E-book: A practical handbook for the health care professional. Edinburgh: Elsevier. https://books.google.com/ books?id=8arRAQAAQBAJ\&dq

Ravindran, A. V., \& da Silva, T. L., 2013. Complementary and alternative therapies as add-on to pharmacotherapy for mood and anxiety disorders: A systematic review. Journal of Affective Disorders, 150(3), pp. 707-19. [DOI:10.1016/j. jad.2013.05.042] [PMID]

Seifi, L., Najafi Ghezeljeh, T. \& Haghani, H., 2017. [The effects of Benson relaxation technique and nature sound's on anxiety in patients with heart failure (Persian)]. Nursing and Midwifery Journal, 15(2), pp. 147-58. http://unmf.umsu. ac.ir/article-1-3036-en.html

Seifi, Z., et al., 2014. The effect of lavender essential oil on anxiety level in patients undergoing coronary artery bypass graft surgery: A double-blinded randomized clinical trial. Iranian Journal of Nursing and Midwifery Research, 19(6), pp. 574-80. [PMID] [PMCID]

Tahmasebi, H., et al., 2015. [The effect of Benson relaxation and aromatherapy on anxiety and physiological indicators in patients undergoing coronary angiography (Persian)]. Nursing and Midwifery Journal, 12(12), pp. 1094-103 http://unmf.umsu.ac.ir/article-1-2028-en.html
Virani, S. S., et al., 2020. Heart disease and stroke statistics-2020 update: A report from the American heart association. Circulation, 141(9), pp. e139-596. [DOI:10.1161/ CIR.00000000000000757] [PMID] 